\title{
Entrevista a Alfredo Fierro
}

A comienzos del siglo XXI ya no quedan psicólogos en el mundo que se atrevan a encarar la antiguamente frecuente tarea de proponer una Psicología completa, una Psicología general que suponga un marco conceptual, teórico y empírico en el que practicar el análisis que le es propio al comportamiento humano en su totalidad, en su género o en su abstracción. En este panorama pocos son los autores españoles que se están atreviendo a distanciarse de lo inmediato y a proponer nuevos intentos de Psicologías a la vieja usanza prepostmoderna. Uno de los más destacados [es] Alfredo Fierro. [Errasti, J.M. (2003) Reseña de "Personalidad, persona, acción” de Alfredo Fierro. Psicothema, 15(2), 336-338].

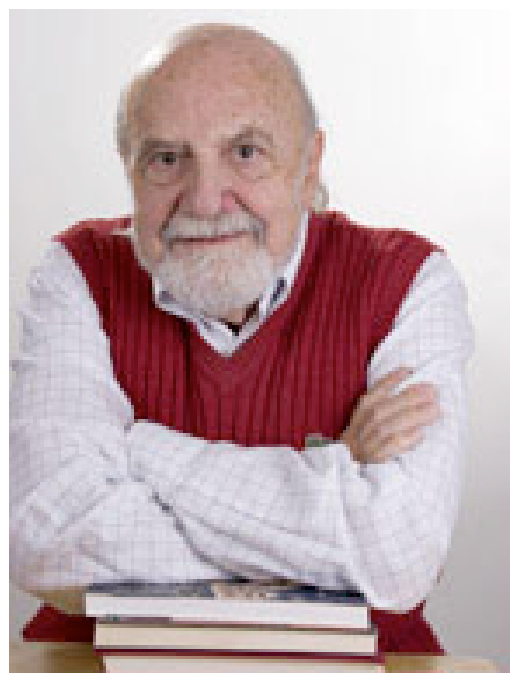

Alfredo Fierro Bardají (Soria, 1936) es licenciado en Derecho por la Universidad de Zaragoza, doctor en Filosofía y Letras, Psicología, por la Universidad Complutense de Madrid, y doctor en Teología por la Universidad Gregoriana de Roma.

Profesor y director de estudios en el Seminario de Zaragoza (19641967), luego director de publicaciones de la Federación Española de Asociaciones Protectoras de Subnormales (1968-1978), desarrolla docencia universitaria en Psicología, específicamente en Psicología de la Personalidad, en la Universidad de Salamanca de 1978 a 1984.

Incorporado a la Universidad de Málaga en octubre de 1984, es el primer Director del Departamento de Psicología, creado en 1985 en esa Universidad. En 1987 accede, mediante oposición, al cuerpo de Catedráticos de Universidad en el área de Personalidad, Evaluación y Tratamiento Psicológicos.

De 1987 a 1993 trabaja en el Ministerio de Educación y Ciencia en tareas de innovación y reforma educativa, primero como Subdirector General de Ordenación Académica, luego Subdirector General de Programas Experimentales y, finalmente, como Director General: Director del Gabinete de la Secretaría de Estado de Educación.

En octubre de 1993 se reincorpora a la Universidad de Málaga donde, desde enero de 1994 a octubre de 2000, es Director del Departamento de Psicología Social y de la Personalidad, y desde marzo de 2001 hasta abril de 2006, Decano de la Facultad de Psicología. Llegada la edad de la jubilación en octubre de 2007, es nombrado profesor emérito.

Su amplia obra en psicología defiende una psicología objetiva que se posiciona de manera crítica tanto frente al conductismo como a otras tradiciones, sean la fenomenología o el psicoanálisis, sin dejar de tener en cuenta que otras concepciones de la realidad humana distintas de la objetiva aportan una visión de la persona necesaria para su compresión. La de Fierro es una ciencia del sujeto, de la persona, que estudia las conductas objetivas, especialmente aquellas que caracteriza como acciones. Se trata de una "psicología de la acción", entendiendo acción como comportamiento no puramente reactivo, sino de verdad activo, que tiene un efecto sobre la realidad. Ha tratado de conceptualizar especialmente la manera en que se desarrolla una personalidad sana y madura, capaz de gestionar la propia vida a través de cursos de acción que modifican el ambiente y que procuran bienestar.

Hace unos meses publicó en la Universidad de Málaga La construcción de la persona. Estudios para una psicología de la acción y el devenir personal (Universidad de Málaga, 2014, 538 pp.), una colección de textos, algunos inéditos, otros ya publicados, agrupados en cinco secciones temáticas que tratan de dar cuenta, desde distintos aspectos de la persona (su actividad interna, su relación con el entorno, su ciclo vital, el curso de acción que favorece un buen vivir, cuestiones epistemológicas de su estudio) de una psicología de la personalidad entendida como "psicología de la acción". 


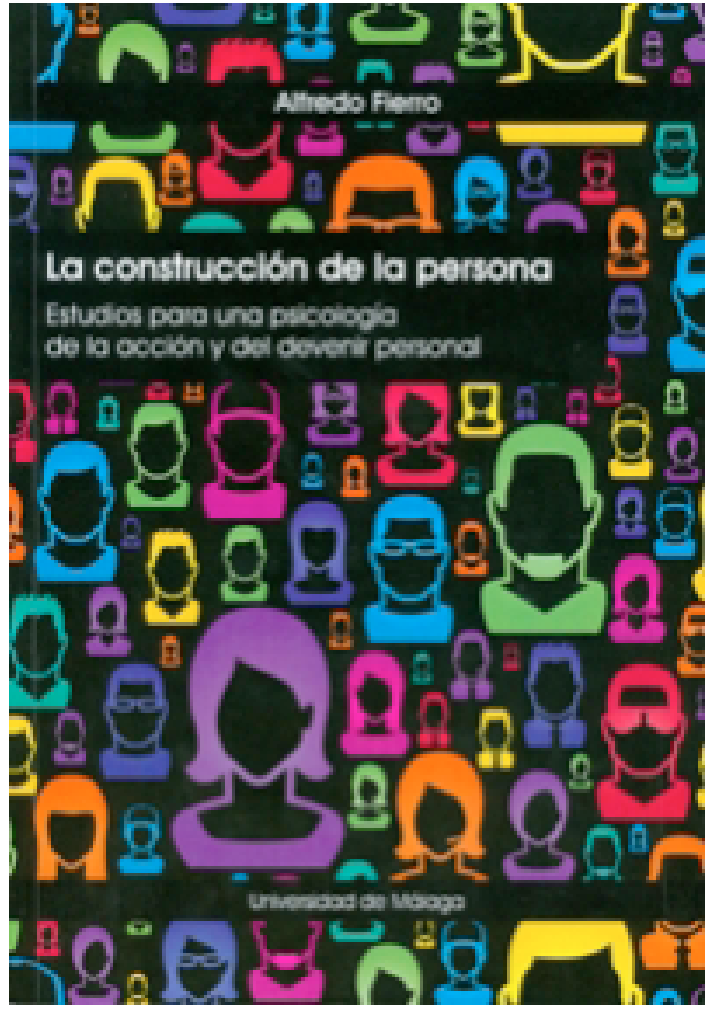

Los textos, que no están ordenados cronológicamente, sino siguiendo un criterio conceptual, escritos con un estilo elegante y preciso, abordan los distintos temas de manera amplia y profunda, evitando simplificar los problemas desde posiciones de escuela, pero tampoco cayendo en el eclecticismo. Se agradece especialmente el uso mesurado e ilustrador de las referencias, que Fierro utiliza para dibujar un cuadro que permite situar histórica y conceptualmente los fenómenos y los problemas teóricos que plantean sin abrumar al lector con listas interminables. Partiendo de la defensa de una psicología objetiva, y en una posición epistemológica desde la que cuestiona una posible integración ingenua entre paradigmas en psicología, su extenso conocimiento de otras maneras de entender a la persona que quedarían en principio fuera del paradigma dominante, como pueden ser la fenomenología y el psicoanálisis, y su crítica del cientificismo en psicología, hacen que sus propuestas sean todo menos planas y dogmáticas.

Aprovechando la reciente publicación de su libro, hemos querido hacerle a Alfredo Fierro unas preguntas y plantearle algunas reflexiones que nos suscitan sus escritos.

Alfredo, con más de cincuenta años de recorrido profesional, y habiendo vivido en primera persona todo el proceso de institucionalización de la Psicología en España, nos interesa mucho saber cuál es su visión de este recorrido que ha cambiado tanto el panorama académico y profesional.

Se ha ganado un espacio institucional y social. Las Facultades de Psicología y los Colegios de Psicólogos, inexistentes hace cincuenta años, se han desarrollado con prestigio en sus respectivos ámbitos, el universitario y el profesional. Y, más importante todavía, el trabajo de psicólogos y psicólogas es reconocido en muy distintas esferas de actuación, no sólo en la clínica. Solo cabe un juicio muy positivo sobre ese proceso.

A lo largo de varios de los textos que contiene este volumen se hace una crítica de una manera encorsetada de entender la empresa científica y de un cierto abandono de lo teórico en aras del pragmatismo clínico ¿Cree que la progresiva desaparición en los planes de estudio de Psicología de las asignaturas tradicionalmente relacionadas con el área de humanidades (la filosofía, la sociología, la antropología...) ha tenido algo que ver con un cierto empobrecimiento de la forma de abordar el psicólogo la compleja realidad que estudia?

Ha habido enriquecimiento en orden a la profesionalidad, al "saber hacer", pero también, es cierto, empobrecimiento por otros flancos. A los alumnos siempre les he dicho: "el psicólogo que sólo sabe psicología ni psicología sabe”. El empobrecimiento ¿se debe a la desaparición de asignaturas de "humanidades"? Puede que en parte sí. Pero en estudios de cuatro años no es posible a la vez intensificar la formación en ellas y en una psicología a la vez científica y práctica. Mi consejo al respecto es que los estudiantes tengan otros contactos con la realidad social y humana a través de lecturas de sociología o antropología, de novela y poesía, o a través del cine. No todo puede hacerse. Pero al menos una "afición" entre esas le es indispensable al psicólogo.

Defiende una psicología epicúrea, "que se decante por la felicidad", cuestionando la pretensión de hacer una ciencia libre de valores que se pretendería imparcial frente a las condiciones externas que favorecen el sufrimiento. En ese sentido nos parece que estaría tomando distancia de algunos planteamientos de psicología positiva, que también apuntarían a la "felicidad" como objetivo propio de una ciencia psicológica pero que con frecuencia toman la realidad como algo dado a lo que sólo habría que saber adaptarse para ser feliz ¿Cuáles serían los puntos de encuentro y desencuentro de esta psicología epicúrea que usted defiende con la llamada psicología positiva? 
Punto de encuentro: un horizonte de felicidad, de dicha. Mis mayores reservas respecto a esa psicología "positiva" están en su "buenismo", su optimismo metafísico, la suposición de que todo a fin de cuentas redunda en bien de la persona. Con eso se desconocen los aspectos dramáticos, a veces trágicos, de la existencia. Algunos libros de autoayuda llegan en eso a extremos rayanos en el delirio de una subjetividad omnipotente.

Aborda en uno de los textos la cuestión de la relación mente-cerebro. En los últimos tiempos se está difundiendo un modelo "cerebrocentrista" que reduce lo comportamental a la actividad cerebral. Por otro lado, el auge de los psicofármacos se sostiene dentro de la psiquiatría en una concepción del trastorno mental como deficitario funcionamiento cerebral, siendo la hipótesis del desequilibrio en el balance de neurotransmisores el ejemplo más potente. Nos interesaría conocer su opinión sobre este estado de cosas que relegaría la intervención psicológica a mero apoyo en el tratamiento de trastornos que se conciben como una enfermedad más, ¿cree que desde la Psicología se está combatiendo con herramientas teóricas adecuadas al avance de ese reduccionismo?

Estoy en contra de considerar los trastornos como "enfermedades" y en contra de cualquier reduccionismo. Que no haya "mente" o conducta superior sin cerebro no valida un enfoque sólo cerebral. Los nuevos psicofármacos parecen estar resucitando antiguos conflictos entre ciertos psiquiatras y psicólogos. Pero la cuestión de competencias acabará por resolverse como ya sucedió en los años 60 y 70.

Señala que las diferencias entre las personas aumentan con el paso del tiempo por la acumulación de experiencia y que por ello en las etapas tardías de la vida existe una mayor diferenciación que hace que los patrones de envejecimiento varien mucho de unos individuos a otros. Hace hincapié en el curso de la vida del individuo más que en un ciclo vital común para todos, resaltando así la relevancia de la acción autodeterminada para entender la diversidad interindividual ¿No se minimiza en esta visión el peso que pueden llegar a tener acontecimientos que suelen ir de manera común asociados a las etapas avanzadas de la vida y que pueden sobrepasar las capacidades de afrontamiento de sujetos que hasta entonces se han desenvuelto con soltura? Pensamos en acontecimientos como la muerte de personas significativas, la aparición de dolencias físicas más o menos graves pero limitantes, la pérdida de refuerzos sociales tras el retiro...

Estos acontecimientos son frecuentes en la edad mayor, pero no universales. No todas las personas mayores se quedan viudas, ni tienen serias dolencias. Tampoco la jubilación significa por fuerza pérdida de refuerzos sociales; a veces, al contrario, proporciona nuevos refuerzos. La edad mayor trae duelos, pero también nuevas fuentes de gozo: los nietos. Verdad es que la vida es injusta siempre, incluso en la enfermedad final y/o en la muerte; y que el curso de la acción puede no haber servido ni para un buen envejecer ni para un sereno morir. Y por supuesto enfermedades, duelos, discapacidad pueden significar desafíos bien difíciles de afrontar. Cada edad hay que aprenderla; y no se aprende a ser hombre o ser mujer de una vez por todas.

Usted defiende que la noción de salud mental y por tanto la psicopatología no son una impostura científica, aunque sean conceptos no libres de valores. Conceptualiza la salud mental como potencial de autocuidado que dirige la acción del sujeto al logro de una experiencia satisfactoria de la vida. En el modelo bidimensional de salud mental que usted desarrolla y sobre el que se está investigando en la Universidad de Málaga, se describe la salud (comporta)mental en relación con el bienestar subjetivo de la persona y con la adaptación social. Considera, frente a las amplias críticas recibidas por el DSM, que este último sistema diagnóstico recoge las dos dimensiones mencionadas cuando define el trastorno mental. Sin embargo, si tomamos como muestra el diagnóstico del TDAH, los criterios utilizados por el DSM no parecen tomar en cuenta la subjetividad del interesado, sino que es el entorno (padres y profesores) el que decide que el niño sufre un trastorno en base a la pobre adaptación escolar o familiar que el evaluado muestra, aunque no exista un malestar subjetivo primario. ¿No le parece a usted que pese a las declaraciones de intenciones los sistemas diagnósticos en uso muchas veces toman partido por una adaptación social (mal)entendida como ajuste unidireccional de la persona al medio?

Sí, desde luego. Pienso que el sistema DSM es conservador en lo social y también en lo científico; que mantiene la tendencia a la medicalización y a crear síndromes con el mero hecho de diagnosticarlos. 
Tras describir la convivencia en psicología de diferentes paradigmas, se posiciona críticamente sobre la posibilidad de la integración entre dos de ellos (el conductista y el psicoanalítico) con el argumento de que tal integración no es realmente otra cosa que la asimilación de uno por otro. Tal asimilación cancelaría uno de los paradigmas, con lo que eso supone de eliminación de toda la teoría que lo acompaña y la incorporación de técnicas sin teoría en un eclecticismo que si bien se justifica en la clínica "por el bien del paciente", le hace a usted temer que la psicología derive hacia una mera "tecnología del comportamiento" en vez de comprometerse en el esclarecimiento de la condición humana. Afirma usted que esta práctica sin teoría puede derivar en curanderismo. Pero si las prácticas derivadas de ambos paradigmas de alguna manera "curan”, son efectivas, es tal vez porque, siguiendo su modelo de psicopatología de ciclos cerrados de acción, distintos enfoques psicoterapéuticos consiguen romper esa especie de círculo vicioso del ciclo cerrado de acción y restaurar un curso abierto de lo conductual, ¿cuáles serían los factores que lo explicarían? ¿habría factores comunes que darían cuenta de la efectividad de las distintas psicoterapias?

No temo a las tecnologías, tampoco a las del comportamiento o las del yo. Pero ni en economía ni en política las tecnologías lo son todo. La psicología -entiendo- ha de contribuir a esclarecer la condición humana y no dejar eso a la filosofía, a los ensayistas o a las varias antropologías. Debería haber y desarrollarse una antropología psicológica, comportamental. En ella habrían no tanto de integrarse, cuanto de complementarse sin eclecticismo y corregirse en crítica recíproca teorías contrapuestas Éstas no dejan de tener elementos comunes que seguramente dan razón de la efectividad de distintas prácticas clínicas derivadas de ellas, dejando aparte que seudociencia y seudoteorías pueden aplicarse en placebos, que también tienen su efecto.

Como revista de psicología nos interesan sobremanera sus críticas acerca del papel que están jugando tanto las normas de publicación como las políticas de los equipos editoriales en la selección de una manera de hacer ciencia que prima el convencionalismo sobre el pensamiento creativo. Las normas cada vez son más restrictivas, y la política de los índices de impacto de las revistas dirige muchas veces las decisiones editoriales hacia consideraciones que poco tienen que ver con la contribución al avance del conocimiento. Por otro lado, las revistas que no se someten a esos criterios dejan de resultar atractivas a los potenciales autores si estos pretenden hacer carrera académica, por lo que se produce una selección que favorece los criterios más conservadores. Nos gustaría saber si tiene usted alguna sugerencia que pueda contribuir a cambiar este estado de cosas.

He escrito "contra el formato editorial" y me lo han publicado con generosidad que agradecí en una revista, Psicothema, que podía verse criticada en mi artículo. Allí razoné que los índices de impacto, el imperio editorial de las revistas APA, los criterios de la ANECA, han llegado a constituir un círculo cerrado que anquilosa la investigación científica. En ese círculo, no ya Freud, tampoco Piaget o Vigotsky, y ni siquiera Skinner hubieran podido publicar. A ninguno de ellos se le reconocerían hoy sexenios. Me parece un sistema perverso, que favorece a los trepadores de la ciencia y de la Universidad, buscadores de recursos económicos en ella, mientras ahoga no ya sólo las disidencias, sino los hallazgos realmente originales y también el talento. 